\title{
Analyzing Errors Reference to Use of Connectives*
}

\author{
Gökhan ÇETINNKAYA $^{* *}$ Hakan ÜLPER $^{* * *}$ Nihat BAYAT $^{* * * *}$
}

Received: 08 December 2014

Accepted: 22 May 2015

\begin{abstract}
The purpose of this research is to determine errors in usage of connectives by secondary students and to specify to what extent the errors they make in terms of connective's types and their functions quantitatively and qualitatively. The participants of the research consist of 477 students studying in 5-8. grades. Data have been collected by the Connective Knowledge Scale in which there are 36 items. Percentage and frequency calculating has been applied in analyzing of the data. The results revealed that different connectives are misused in different quantities. In addition, the most misused connectives were discourse adverbials and the least were coordinating connectives in terms of their syntactic structure. Also the most misused connectives were comparisons and the least were temporal connectives in terms of their meaning. The results gained from this research has emerged that students have troubles about use of the connectives.
\end{abstract}

Keywords: word knowledge; reading comprehension; writing skills; Turkish language education

\section{Extended Abstract}

Purpose and Significance: The results of descriptive studies intended for usage of false/true or frequency of connectives used by analysing the written outcomes of students determine only the outcomes addressed to the students' skills of usage of connectives. Because of, the connectors used by students in written outcomes are limited by the type, topic or context of texts. The studies about this literature have not an integrated view on the students' knowledge of connectives. The importance of this study is to signalize the integrated view on the students' knowledge of connectives classiffied on the syntactic and semantic properties. In the light of this importance, the aim of this study is, first of all, to detect the errors on the usage of connectors and then is to determine how much students' wrongs change according to the types and functions of connectives in terms of qualitative and quantitive by analysing these errors.

The sub-questions configured on the main aim are below:

1. How is the frequency and range of the students' wrong usage of connectives?

2. How is the frequency and range of students' wrong usage of connectives on the basis of syntantic and semantic properties?

\footnotetext{
* A part of this study was presented as an oral presentation at 3rd World Conference on Educational and Instructional Studies on 06-08 November 2014, Antalya, Turkey.

** Corresponding Author: Assist. Prof. Dr., Niğde University, Niğde, Turkey, gokhancetinkaya76@hotmail.com

**** Assoc. Prof. Dr., Mehmet Akif Ersoy University, Burdur, Turkey, hakanulper@gmail.com

**** Assoc. Prof. Dr.,Akdeniz University, Antalya, Turkey, nihatbayat@gmail.com
}

\section{Citation Information}

Çetinkaya, G., Ülper, H., \& Bayat, N. (2016). Bağlayıcı kullanımına ilişkin yanlışların çözümlenmesi. Kuramsal Ĕgitimbilim Dergisi [Journal of Theoretical Educational Science], 9(2), 198-213. 
Methods: The study sample was composed of 477 students. In total sample 187 students were in middle, 129 students were in higher and 161 students were in lower socioeconomic status. The sample which includes 237 girls and 240 boys are as follows: There were 122 students in fifth grades, 120 students in sixth grades, 119 students in seventh grades and 16 students in eighth grades. Data were collected by an 36-item scale which was developed by researchers. Connectives are divided into 3 categories and under these categories there are 4 sub-categories according to their features. In this context, 3 connectives were selected from these sub-categories and 36 items were obtained from 12 subcategories. Data were analysed by percentage and frequency calculations. Accordingly, first students' incorrect answers were identified. Then, error distribution was determined according to their type and function.

Results: The findings gained from the research revealed that secondary school students had problems about using the connectives. A small number of participants misused 7 connectives in the test consisting of 36 items with regard to the first problem of the study. The participant numbers who used the connectives incorrectly were for "ve (and)” 51, “once (before)” 52, “sonra (after)” 103, “ya da (or)” 129, “çünkü (because)” 133, “öncelikle (first of all)” 141, and “ ve sonraları (afterwards) 147. All these connectives are coordinators except "öncelikle" in terms of their syntactic features. The connectives "ve", and "çünkü" are causalities while other five were temporal connectives in terms of their meaning.

There are 13 connectives that were misused between \%31 and \%50. Two connectives "böylece", and "ilk olarak" misused the most in the group were discourse adverbials. 16 connectives were used incorrectly by more than half of the participants in the test. Those connectives were of 7 subordinations, 6 discourse adverbials, and 3 coordinators for their syntactic features; 5 additives, 5 comparisons, 4 temporals, and 2 contingencies in terms of their meaning.

In classification of their syntactic properties, connectives were used incorrectly 3100 times $(\% 54,2)$ in discourse adverbials, 2983 times $(\% 52,1)$ in subordinators, and 2035 times $(\% 35,6)$ in coordinators. This result indicates the connectives at which students were the best was coordinators for syntactical properties. Comparison connectives were the most incorrect used by the students in their meaning. Comparison connectives were followed by additives, contingencies, and temporal connectives respectively.

Discussion and Conclusions: 477 students participated in the study are not successful enough in using connectives in the test including subordinators, coordinators, and discourse adverbials. This result should be evaluated in consideration of generating text and reading comprehension. Instructions facilitating using of connectives are recommended for the related curriculum followed at schools in accordance to the results of the study. 


\title{
Bağlayıcı Kullanımına İlişkin Yanlışların Çözümlenmesi*
}

\author{
Gökhan ÇETİNKAYA $^{* *}$ Hakan ÜLPER $^{* * *}$ Nihat BAYAT $^{* * * *}$
}

Makale Gönderme Tarihi: 08 Aralık 2014

Makale Kabul Tarihi: 22 Mayıs 2015

ÖZ: Bu araştırmanın amacı ortaokul öğrencilerinin bağlayıcı kullanımlarındaki yanlışları saptamak ve yanlışların bağlayıcıların türüne ve işlevine göre ne düzeyde yapıldığını nicel ve nitel açıdan belirlemektir. Araştırmanın çalışma grubunu 5-8. sınıf düzeyinde öğrenimlerine devam eden 477 öğrenci oluşturmaktadır. Veriler 36 maddeden oluşan Bağlayıcı Bilgi Ölçeği ile toplanmıştır. Verilerin çözümlenmesinde yüzde ve frekans hesaplamalarına başvurulmuştur. Çözümlemeler sonucunda farklı bağlayıcıların farklı miktarlarda hatalı kullanıldığı, yapısal açıdan en fazla söylem belirteci türündeki bağlayıcılarda ve en az yana sıralama bağlayıcılarında, anlamsal açıdan ise en fazla karşıtlık bildiren bağlayıcılarda ve en az zamansallık bildiren bağlayıcılarda hata yapıldığı görülmüştür. Elde edilen bulgular öğrencilerin bağlayıcı kullanımlarında sorunlar yaşadığını ortaya koymuştur.

Anahtar kelimeler: sözcük bilgisi; okuduğunu anlama; yazma becerisi; Türkçe eğitimi

\section{Giriş}

Metin sözcüğünün Fransızcadaki "texte" ya da İngilizcedeki "text" karşılıklarının kökenine baktığımızda, bunların Latincede "kumaş" anlamına gelen textus sözcüğünden geldiğini görmekteyiz. Kumaş nasıl ipliklerden dokunarak bir bütün oluşturuyorsa, metin de kendisini oluşturan ögelerin birbirlerine aşama aşama eklemlenmesiyle, bir "dokuma" süreci sonucunda ortaya çıkar (Onursal, 2003). Metnin yetkin bir biçimde oluşturulması ve okurun metni eksiksiz olarak anlamlandırabilmesi için metnin yapısında bulunması gereken özellikler içinde bağdaşıklık önemli bir işleve sahiptir. Bağdaşıklık sözcüksel ve dilbilgisel ögelerle tümceleri dilbilgisel, mantıksal ve anlamsal olarak bağıntılayan ve böylece alımlayıcı tarafından bir söylem olarak algılanmasını sağlayan bir metinsellik ölçütüdür. Günay $(2013,105)$ metnin tümcelerin basit bir sıralanışı değil, tümceler arası ilişkilerle oluşturulmuş tutarlı bir dilsel yapı olduğunu belirtmekte ve metni şu şekilde açıklamaktadır:

Metin=T1 + B + T2 + B + .. Tn (T: Tümce, B: Bağıntılayan). Bu bağlamda metin dilsel açıdan birbirini izleyen, sıralı ve anlamlı bütünler oluşturan tümceler dizisidir (Günay, 2013, 45). Bir tümceler grubunun metin olup olmadığı ya da metinsel özellik taşıyıp taşımadığı tutarlılık ve bağdaşıklık ögelerine göre değerlendirilebilir. Bir tümce nasıl yalnızca sözcüklerin art arda gelmesi değilse, bir metin de tümcelerin art arda gelmesi değildir. Tümcedeki sözcükler arasında biçimbilimsel bağıntılar (adyüklem uyumu, eylemlerin kişi ve zamana göre çekimi, vb) vardır. Benzer biçimde metin içindeki tümceler arasında da bağıntı ögeleri vardır. Metnin sürekliliği, kavramlar ya da örgeler (motif) arasında kurulabilen nedensellik, karşıtlık ve başka türdeki anlamsal, mantıksal ya da dizimsel ilişkilerle olabilmektedir (Günay, 2013, 46). Bu

\footnotetext{
* Bu çalışmanın bir kısmı 06-08 Aralık 2014 tarihinde Antalya'da yapılan 3rd World Conference on Educational and Instructional Studies sempozyumunda sözlü bildiri olarak sunulmuştur.

** Sorumlu Yazar: Yrd. Doç.. Dr., Niğde Üniversitesi, Niğde, Türkiye, gokhancetinkaya76@hotmail.com

*** Doç. Dr., Mehmet Akif Ersoy Üniversitesi, Burdur, Türkiye, hakanulper@gmail.com

**** Doç. Dr., Akdeniz Üniversitesi, Antalya, Türkiye, nihatbayat@gmail.com
} 
ilişsiler bağdaşıklık ilişkileri olarak tanımlanabilir. Bu ilişkileri kurmaya yarayan araçlar kendi içinde çeşitlilik göstermektedir.

Bağdaşıklık araçları Halliday ve Hasan (1976) tarafından dilbilgisel (grammatical) ve sözcüksel (lexical) olmak üzere iki ulamda sınıflandırılmıştır. Dilbilgisel araçlar gönderim (reference), eksiltme (ellipsis), değiştirim (substitution) ve bağlayıcıları (conjunctions) içerirken, sözcüksel bağdaşıklık yineleme (reitaration) ve eşdizimlilik (collocation) kavramlarını içermektedir. Metin/söylem yapısının irdelendiği çalışmalara göre, bağdaşıklık ve tutarlılığı en açık olarak ortaya koyan dilsel ögeler bağlayıcılardır. Bağdaşıklık ve tutarlılık, eşadlılık, eşanlamlılık, zıt anlamlılık gibi sözlüksel bağlantılarla sağlanabilse de bağlayıcılar, söylemdeki bağdaşıklık ve tutarlılık bağlarını herhangi bir kuşkuya yer vermeden açıkça ortaya koyan sözcükler olduklarından çoğu söylem kuramında önemli bir yere sahiptir (Kurtul, 2011, 55). Bağlayıcılar düşünceler arasındaki mantıksal ilişkileri işaret etmek için kullanılır (Kintsch \& van Dijk, 1978). Örneğin nedensel ilişkiler çünkü, bu nedenle, -dAn dolay1 vb. nedensel bağlayıcılarla, zamansal ilişkiler -ArAk, önce, ilk olarak vb. bağlayıcılarla, karşıtlık ilişkileri -(n)E rağmen, oysa, buna karşın vb. bağlayıcılarla ve genişleme ilişkileri -ken, ya da, öte yandan vb. bağlayıcılarla işaretlenir. Tümcelerin birlikte kullanılması söylemi hem üreten hem de yorumlayan için anlamlı ilişkiler oluşturur. Bağlayıcılar söylemdeki önermeleri bağlayan sözcük ya da öbeklerdir. Bağlayıcılar iki önerme arasındaki anlamsal ilişkileri belirler (Turan, Zeyrek, \& Bozşahin, 2012). Başka bir deyişle metin içindeki olaylar ve durumlar arasındaki ilişkiler bağlayıcı yapılarla sağlanabilir (Uzun, 2006).

Anlama sürecini açıklamaya yönelik araştırmalar metnin küçük yapısını anlama sürecinde tümce bağlarını ve mantık bağlarını anlamanın önemine vurgu yapar (bkz. Güneş, 2014). "Bağlayıcılar metnin küçük ölçekli yapısında ardışık sözceler arasındaki anlamsal ilişkilerin metnin alıcısı, yani okuyucusu ya da dinleyicisi tarafından açık olarak algılanmasını sağlayan belirginleştirici ögelerdir. Bu rolleriyle ardışık sözceler arasındaki eklem yerlerini işaret eder ve eklemlemenin sonucunda ortaya çıkan küçük ölçekli anlam ilişkilerini tanımlarlar. Bağlaçların kullanımındaki azlığın yanı sıra, bağlaç kullanmama ya da yanlış kullanma durumu öğrenci metinleri için bir metinleştirme sorunu olarak karşımıza çıkmaktadır. Bağlaç kullanımında sorunlar gözlenen öğrenci metinlerinde sözceler arasında anlamsal kopukluklar biçiminde ya da iki sözce arasındaki ilişkinin birden çok mantıksal bağa (neden-sonuç/amaç; karşıtlık/karşılaştırma gibi) işaret etmesi sonucu oluşacak "bulanık anlamlılık”da gözlenebilir.” (Uzun, 2006, 700).

Metnin yorumlanabilmesi dil birimleriyle gerçekleştirilen dilsel bağlar yoluyla düşünsel bağlara ulaşmayı gerektirdiği için bu tür bağlantıların üretici ve alımlayıcı tarafından çok iyi bilinmeleri ve içselleştirilmeleri gerekir (Dilidüzgün, 2008, 68). Bağlayıcı bilgisinin okuduğunu anlamayla olan ilişkisini sorgulamaya yönelik çalışmaların sonuçları öğrencilerin bağlayıcı bilgisi ile metni anlamlandırma durumları arasında doğrusal ve güçlü bir ilişkinin varlığını açıkça ortaya koymaktadır (Crosson ve Lesaux, 2013; Duggleby, Tang \& Kuo-Newhouse, 2015). Öte yandan, bağlayıc1 
kullanımı ile öğrenciler tarafından üretilen metinlerin niteliği arasındaki ilişkiyi sorgulayan çalışmaların sonuçları incelendiğinde, bağlayıcıların kullanım sıklıkları ile yazma kalitesi arasında ilişki olmadığı, bağlayıcıları doğru kullanma becerisiyle yazma kalitesi arasında ise güçlü bir ilişki olduğu görülmektedir (Cook, 1989; McCarthy, 1991; Jin, 2001; Bae, 2001; Coşkun, 2005; Karatay, 2010; Duggleby, Tang, \& KuoNewhouse, 2015).

Diğer yandan öğrencilerin bağlayıcı kullanımlarına ilişkin doğrudan ya da dolaylı olarak bir sonuç ortaya koyan çalışmaların, öğrencilerin yazılı anlatımlarında bağdaşıklık unsurlarını kullanım durumları ve tutarlılık düzeylerini belirlemeye (Seçkin, Arslan \& Ergenç, 2014), bağdaşıklık araçlarını işlevlerine göre yazılı anlatımlarında kullanma becerilerini belirlemeye (Can, 2012), bağdaşıklık araçlarını kullanma düzeyi ile tutarlı metin yazma arasındaki ilişkiyi incelemeye (Karatay, 2010), öğrencilerin yazılı anlatımlarında kullandıkları bağlayıcıların sınıf düzeylerine göre sıklıklarını ve uygunluklarını incelemeye (Çetinkaya, Ülper, \& Hamzadayı, 2014) ya da Türkçe metinlerde yer alan bağlayıcı türleri ile öğrencilerin okuduğunu anlama durumları arasındaki ilişkiyi (Gençer, 2013) sorgulamaya odaklanan çalışmalar olduğu görülmektedir.

Öğrencilerin yazılı anlatım ürünlerini çözümleyerek kullanılan bağlayıcıların sıklıklarına ya da doğru ve uygun kullanımına yönelik betimleyici çalışmaların sonuçları öğrencilerin bağlayıcı kullanım becerisine dönük yalnızca varolan ürün üzerinden bir belirleme yapar. Çünkü, öğrencilerin yazılı anlatımlarında işe koştukları bağlayıcılar metnin türü, konusu ve bağlamı ile sınırlıdır. Bu durumda, öğrencilerin bağlayıcı bilgisine dönük bütüncül bir görünüm sunmaz. Bu çalışmanın önemi, gerek sözdizimsel gerek anlamsal özelliklerine göre sınıflandırılan bağlayıcılara ilişkin öğrencilerin bağlayıcı bilgisine dönük bütüncül bir görünün sunması açısından belirginleşmektedir.

Belirtilen önem doğrultusunda, bu araştırmanın amacı ortaokul öğrencilerinin bağlayıcı kullanımına ilişkin yanlışlarını saptamak ve bu yanlışları çözümleyerek bağlayıcıların türüne ve işlevine göre ne düzeyde yanlış yapıldığını nitel ve nicel açıdan saptamaktır. Çalışmanın temel amacı doğrultusunda yanıt aranan alt problemler şunlardır:

1. Öğrencilerin yanlış kullandıkları bağlayıcıların sıklık ve dağılımları nasıldır?

2. Bağlayıcıların yanlış kullanılma sıklık ve dağılımları yapısal ve anlamsal ulamlara göre nasıl bir dağılım göstermektedir?

\section{Yöntem}

\section{Araştırma Deseni}

$\mathrm{Bu}$ araştırmada, ortaokul öğrencilerinin bağlayıcı kullanımına ilişkin yanlışlarını saptamak ve bu yanlışların bağlayıcı türüne ve işlevine göre nasıl bir dağılım gösterdiğini saptamak amaçlandığından, tarama modeli kullanılmıştır. 


\section{Çalışma Grubu}

Çocuklar yaklaşık 5 yaşlarında bağlayıcıları kullanmaya başlar (Spooren ve Sanders, 2008). Daha sonra bağlayıcıların edinimi aşamalı bir gelişim gösterir. Genellikle "ve" gibi genişleme ilişkisi bildiren bağlayıcılar ilk olarak edinilir. Bu tür bağlayıcıları sırasıyla zamansal, nedensel ve karşıtlık bildiren bağlayıcılar izler. Konuşma sürecinde çocukların bağlayıcıları kullanmaya başlaması, çocuk okurların bağlayıcılardan yararlanmaya başlayabileceğine işaret eder. Öte yandan, bağlayıcıların sözel ve yazılı metin üretim sürecinde uygun kullanımı ve anlaşılmasına yönelik gelişim yıllarca sürer (Irwin ve Pulver, 1984). Bu durum, 5-8. sınıf düzeyindeki öğrencilerin bağlayıcı kullanma becerilerine sahip olmaları gerektiğine işaret eder. Bu araştırmanın 5-8. sınıflar üzerinden yapılması bu nedenlere dayanmaktadır.

Bu bağlamda, Burdur ili merkezde yer alan üç ortaokulun 5-8. sınıflarının birer şubesi seçkisiz biçimde çalışma grubu olarak alınmıştır. Toplam 477 öğrenciden oluşan çalışma grubunun 187'si orta, 129'u üst ve 161 de alt sosyo-ekonomik düzeydedir. 237'si kız 240'1 ise erkek olan katılımcıların sınıflara göre görünümü şöyledir: Beşinci sınıflar 122, altıncı sınıflar 120, yedinci sınıflar 119 ve sekizinci sınıflar 116 öğrenciden oluşmaktadır.

\section{Veri Toplama Aracı}

Veri toplama aracı olarak araştırmacılar tarafından geliştirilmiş olan 36 maddelik bir ölçek kullanılmıştır. Yukarıda da belirtildiği gibi bağlayıcılar yapısal özelliklerine göre 3 ana ulama ve bu ulamlar altında anlamsal özelliklerine göre 4 alt ulama ayrılmaktadır. Bu bağlamda 12 alt ulam ve bu alt ulamların her birinden üçer bağlayıcı seçilerek 36 madde elde edilmiştir. Elde edilen 36 maddede yer alan bağlayıcılar Tablo 1 'de gösterilmiştir. 
Tablo 1

Yapısal ve anlamsal özelliklerine göre testte kullanılan bă̆layıcılar

\begin{tabular}{|c|c|c|c|}
\hline \multirow{2}{*}{ Anlamsal } & \multicolumn{3}{|c|}{ Yapısal } \\
\hline & Alta Siralama & Yana Siralama & Söylem Belirteci \\
\hline \multirow{3}{*}{ Zamansal } & -dIğI zamanlarda & Önce & Öncelikle \\
\hline & -ArAk & Sonra & Böyle bir durumda \\
\hline & -(n)A karşı çıkıp & Sonraları & İlk olarak \\
\hline \multirow{3}{*}{ Nedensel } & -mAk için & Çünkü & Neden olarak \\
\hline & -dIğI için & ve & Bu nedenle \\
\hline & -dAn dolayı & Diye & Böylece \\
\hline \multirow{3}{*}{ Karşıtlık } & -(n)A karşın & Oysa & Buna karşıı \\
\hline & -(n)E rağmen & Söz gelimi & Halbuki \\
\hline & $-(y) s E d A$ & Sanki & Aksi takdirde \\
\hline \multirow{3}{*}{ Genişleme } & -Ip & Ya da & Bununla birlikte \\
\hline & -ken & Hem- hem de- & Ayrica \\
\hline & -DIĞI gibi & Derken & Öte yandan \\
\hline
\end{tabular}

Tablo 1'de yer alan bağlayıcılarla oluşturulan maddeler, biri doğru yanıt olacak biçimde dört seçenekli olarak düzenlenmiştir. Hazırlanan veri toplama aracı özellikle seçeneklerin nitelikleri bakımından alan uzmanlarına gösterilerek görüş alınmış ve gerekli düzeltmeler yapılmıştır. Böylelikle aracın geçerliği sağlanmaya çalışılmıştır. Bu araçtan toplanacak olan veriler bir puanlamaya tabi tutulmayacağ1 için güvenirlik çalışması yapılmamış, sadece geçerlik çalışması yeterli görülmüştür. Bu ölçme aracı aşağıdaki örneklerde görüldüğü gibi yapılandırılmıştır:

1. Yola çıkmadan önce yeterli miktarda erzak alman lazım. kamp yeri civarında market, bakkal ya da benzeri bir şey yok.

$\mathrm{Bu}$ cümlede boş bırakılan yere aşağıdakilerden hangisi gelir?

a) Sanki

b) Belki

c) Çünkü

d) Fakat 
2. Evlilikleri büyük bir heyecan ve mutluluk içinde başladı. Sonraları

$\mathrm{Bu}$ cümlede boş bırakılan yere aşağıdakilerden hangisi gelir?

a) Ortaya çıkan geçim sıkıntısı, çevre baskısı, anlamsız ritüeller o mutluluğu yerle bir etti.

b) Uzun süren iş seyahatlerinin etkisiyle kendisini yorgun hissetmeye başladı.

c) Tanıştığı insanlardan evlilikler üzerine yeni yeni şeyler öğrendi.

d) Çevresindeki evliliklerin de heyecan ve mutluluk içinde olup olmadığını merak etmeye başladi.

3. demek ki hayatının geri kalanını burada geçirecek.

Bu cümlede boş bırakılan yere aşağıdakilerden hangisi gelmez?

a. Bu ev için çok zaman, emek ve para harcadı,

b. Bu kasabaya gelmek için yıllardır çalıştığı işi bıraktı,

c. Birkaç gündür odasından dışarı çıkmıyor,

d. Şehirdeki evini ve arabasını satarak bu köye yerleşti.

\section{Verilerin Çözümlenmesi}

Verilerin çözümlenmesinde yüzde ve sıklık (frekans) hesaplamasına başvurulmuştur. Buna göre öncelikle öğrencilerin yanlış yanıtları belirlenmiştir. Daha sonra yanlışların bağlayıcı türlerine ve işlevlerine göre dağılımı belirlenmiştir.

\section{Bulgular}

Çalışmanın bu bölümünde, araştırmanın soruları çerçevesinde çalışma grubunda yer alan öğrencilerden elde edilen verilerin çözümlenmesi sonucu ortaya çıkan bulgulara ve yorumlara yer verilmiştir.

\section{Öğrencilerin Yanlış Kullandıkları Bağlayıcıların Sıklık ve Dağılımları}

Araştırmanın birinci sorusu “Öğrencilerin yanlış kullandıkları bă̆layıcıların sıklık ve dă̆glımları nasıldır?" biçiminde oluşturulmuştur.

$\mathrm{Bu}$ soruya yanıt aramak için çalışma grubunda yer alan öğrencilerin 36 maddelik bağlayıcı ölçeğine verdikleri yanlış yanıtlar çözümlenmiştir. Ortaya çıkan bulgular, yanlış yapılma oranları çerçevesinde \%10-30, \%31-50 ve \%51-81 aralıklarında gruplandırılarak sınıflandırılmış ve üç ayrı tabloda sunulmuştur. Elde edilen bulgular aşağıda Tablo 2, 3, 4’te gösterilmektedir: 
Tablo 2

Yanlış kullanılma oranı \% 10-30 arası olan bă̆layıcılar

\begin{tabular}{lccc}
\hline Bağlayıcılar & Öğrenci sayısı & Yanlı̧s sayısı & Yanlı̧ oranı \\
\hline Ve & 477 & 51 & 10.7 \\
Önce & 477 & 52 & 10.9 \\
Sonra & 477 & 103 & 21.5 \\
Ya da & 477 & 129 & 27.0 \\
Çünkü & 477 & 133 & 27.8 \\
Öncelikle & 477 & 141 & 29.5 \\
Sonraları & 477 & 147 & 30.8 \\
\hline
\end{tabular}

Tablo 2'ye göre, 7 ayrı bağlayıcının 51-147 aralığında katılımcı tarafından yanlış kullanıldığı görülmektedir. Yanlış kullanan öğrencilerin yüzdelik oranları ise \%10.730.8 aralığındadır.

Tablo 3

Yanlış kullanılma oranı \% 31-50 arası olan bağlayıcılar

\begin{tabular}{lccc}
\hline Bağlayıcılar & Öğrenci sayısı & Yanlışsayısı & Yanlı̧̧ oranı \\
\hline Diye & 477 & 182 & 38.1 \\
-DIĞI gibi & 477 & 187 & 39.2 \\
-Ip & 477 & 192 & 40.2 \\
Derken & 477 & 193 & 40.4 \\
-(y)sE dA & 477 & 199 & 41.7 \\
Neden olarak & 477 & 200 & 41.9 \\
Aksi takdirde & 477 & 207 & 43.3 \\
-dAn dolayı & 477 & 208 & 43.6 \\
Halbuki & 477 & 225 & 47.1 \\
Sanki & 477 & 229 & 48 \\
-mAk için & 477 & 235 & 49.2 \\
Böylece & 477 & 237 & 49.6 \\
İlk olarak & 477 & 237 & 49.6 \\
\hline
\end{tabular}

Tablo 3'e göre, 13 ayrı bağlayıcının 182-237 aralığında katılımcı tarafından yanlış kullanıldığı görülmektedir. Yanlış kullanan öğrencilerin yüzdelik oranları ise \%38.1-49.6 aralığındadır. 
Tablo 4

Yanlış kullanılma oranı \% 51-81 arası olan bă̆layıcılar

\begin{tabular}{lccc}
\hline \multicolumn{1}{c}{ Bağlayıcılar } & Öğrenci sayısı & Yanlı̧s sayısı & Yanlı̧̧ oranı \\
\hline Hem- hem de- & 477 & 244 & 51.1 \\
-(n)E rağmen & 477 & 244 & 51.1 \\
-dĬ̆I zamanlarda & 477 & 254 & 53.2 \\
-ken & 477 & 260 & 54.5 \\
Oysa & 477 & 266 & 55.7 \\
Ayrıca & 477 & 267 & 55.9 \\
-(n)A karşın & 477 & 273 & 57.2 \\
Öte yandan & 477 & 278 & 58.2 \\
-dIğI için & 477 & 281 & 58.9 \\
-ArAk & 477 & 289 & 60.5 \\
Böyle bir durumda & 477 & 290 & 60.7 \\
Bu nedenle & 477 & 295 & 61.8 \\
Söz gelimi & 477 & 306 & 64.1 \\
Bununla birlikte & 477 & 334 & 70.0 \\
-(n)A karşı çıkıp & 477 & 361 & 75.6 \\
Buna karşın & 477 & 389 & 81.5 \\
\hline
\end{tabular}

Tablo 4'e göre, 16 ayrı bağlayıcının 244-389 aralığında katılımcı tarafindan yanlış kullanıldığı görülmektedir. Yanlış kullanan öğrencilerin yüzdelik oranları \%51.181.5 aralı̆̆ındadır.

\section{Bağlayıcıların Yanlış Kullanılma Sıklık ve Dağılımlarının Yapısal ve Anlamsal Ulamlara Göre Dağılımı}

Araştırmanın ikinci sorusu "Bağlayıcıların yanlış kullanılma sıklık ve dă̆llımları yapısal ve anlamsal ulamlara göre nasıl bir dă̆llım göstermektedir?” biçiminde oluşturulmuştur.

Bu soruya yanıt aramak için çalışma grubunda yer alan öğrencilerin 36 maddelik bağlayıcı ölçeğine verdikleri yanlış yanıtlar çözümlenmiştir. Elde edilen bulgular bağlayıcıların yapısal özellikleri ve alt ulamlarına göre Tablo 5'te ve anlamsal özelliklerine göre Tablo 6'da gösterilmektedir: 
Tablo 5

Bağlayıcıların yanlış kullanılma oranlarının yapısal ve alt ulamlara göre dağılımı

\begin{tabular}{|c|c|c|c|c|c|}
\hline Bă̆layıcı ulamları & $f$ & $\%$ & Anlamsal ulamlar & Yanlış sayısı & Yanlış oranı \\
\hline \multirow{4}{*}{ Söylem belirteci } & \multirow{4}{*}{3100} & \multirow{4}{*}{54.2} & Zamansal & 668 & 46.7 \\
\hline & & & Nedensel & 732 & 51.2 \\
\hline & & & Karşıtlık & 821 & 57.4 \\
\hline & & & Genişleme & 879 & 61.4 \\
\hline \multirow{4}{*}{ Alta sıralama } & \multirow{4}{*}{2983} & \multirow{4}{*}{52.1} & Zamansal & 904 & 63.2 \\
\hline & & & Nedensel & 724 & 50.6 \\
\hline & & & Karşıtlık & 716 & 50.0 \\
\hline & & & Genişleme & 639 & 44.7 \\
\hline \multirow{4}{*}{ Yana siralama } & \multirow{4}{*}{2035} & \multirow{4}{*}{35.6} & Zamansal & 302 & 21.1 \\
\hline & & & Nedensel & 366 & 25.6 \\
\hline & & & Karşıtlık & 801 & 56.0 \\
\hline & & & Genişleme & 566 & 39.6 \\
\hline
\end{tabular}

Tablo 5 incelendiğinde, yapısal sınıflandırma içinde "söylem belirteci”nin \%54.2 oranla üç ulam arasından en fazla yanlışın yapıldığı tür olduğu görülmektedir. Söylem belirtecinin altında yer alan anlamsal türler incelendiğinde, en fazla yanlış yapılan tür \%61.4 oranla "genişleme" bildiren bağlayıcılardır. İkinci olarak yapısal sınıflandırma içinde en fazla yanlışın yapıldığı tür \%52.1 oranla "alta sıralama" bağlayıcılarıdır. Alta sıralama bağlayıcılarının altında yer alan anlamsal sınıflandırmaya bakıldığında, en fazla yanlış yapılan tür \%63.2 oranla “zamansal” anlam içeren bağlayıcılardır. Son olarak, yapısal sınıflandırma içinde en az yanlışın yapıldığı tür \%35.6 oranla "yana sıralama" bağlayıcıları olmuştur. Bu grubun altında yer alan anlamsal türler incelendiğinde en fazla yanlışın \%56.0 oranla "karşıtlık" bildiren bağlayıcı türünde yapıldığı görülmektedir.

Tablo 6

Bağlayıcıların yanlış kullanılma oranlarının anlamsal ulamlara göre dă̆ılımı

\begin{tabular}{lcc}
\hline Anlamsal Ulamlar & Yanlış Sayısı & Yanlış Oranı \\
\hline Karşıtlık & 2338 & 54.5 \\
Genişleme & 2084 & 48.5 \\
Nedensel & 1822 & 42.4 \\
Zamansal & 1874 & 40.8 \\
\hline
\end{tabular}


Tablo 6 incelendiğinde, karşıtlık bildiren bağlayıcıların \%54.5 oranla en sık yanlış kullanıldığı, bunu sırasıyla genişleme, nedensellik ve zamansal ilişki bildiren bağlayıcıların takip ettiği görülmektedir.

\section{Sonuç ve Tartışma}

Ortaokul öğrencilerinin bağlayıcı kullanımına ilişkin edimlerindeki yanlışları saptamayı ve bu yanlışları çözümleyerek yapısal ve anlamsal özellikleri temelinde bağlayıcıların ne düzeyde yanlış kullanıldığını nitel ve nicel açıdan ortaya koymayı amaçlayan bu araştırmada, 5-8. sınıf düzeyinde öğrenimlerini sürdüren 477 öğrencinin 36 maddelik ölçeğe verdikleri yanıtlar incelenmiştir. Araştırmanın veri tabanından elde edilen bulgular ortaokul öğrencilerinin bağlayıcıları kullanma konusunda sorun yaşadığını ortaya koymuştur. Coşkun'un (2005) ilköğretim öğrencilerinin öyküleyici anlatımlarını bağdaşıklık, tutarlılık ve metin elementleri açısından incelediği çalışmasının sonuçları da benzer biçimde öğrencilerin bağdaşıklık araçlarını kullanma konusunda önemli sorunlar yaşadıklarını ortaya koymaktadır. Belirtilen sorunlar içinde bağlayıcıların öğrencilerin yazılı anlatımlarında anlam ve işlevine uygun olmayan bir biçimde ya da gerekli olmayan durumlarda kullanıldığg belirtilmektedir.

Birinci araştırma sorusu çerçevesinde bağlayıcıların her birinin katılımcılar tarafından yanlış yapılma sıklık ve yüzdelik oranlarına bakıldığında testte yer alan 36 bağlayıcıdan 7'sinin az miktarda katılımcı tarafından yanlış kullanıldığg görülmüştür. Bu bağlayıcılardan “ve” 51, “önce” 52, “sonra” 103, “ya da” 129, “çünkü” 133, “öncelikle” 141 ve "sonraları" 147 katılımcı tarafından yanlış kullanılmıştır. Katılımcıların en başarılı olduğu bu bağlayıcıların yapısal ve anlamsal özelliklerine bakıldığında "öncelikle” bağlayıcısı dışında diğer altısının yana sıralama bağlayıcıları olduğu görülmektedir. Ayrıca "ve” ile "çünkü" bağlayıcıları nedensellik, diğer beş bağlayıcı ise zamansallık bildiren bağlayıcılardır. Coşkun'un (2005) çalışmasında 5. sınıf öğrencilerinin yazılı anlatımlarında "ve" ayrıca "sonra" bağlayıcılarını gereksiz ve sıklıkla kullandıkları belirtilmektedir. Coşkun (2005) bu durumun öğrencilerin art arda gelen ve hızlı gelişen olaylar arasında bağlantı kurma çabası içinde olmalarından kaynaklanıyor olabileceğini öne sürmektedir. Buna ek olarak, öğrencilerin duruma ve bağlama uygun diğer mantıksal ilişkileri sağlayan bağlayıcıları ya da onların anlam ve işlevini tam olarak bilmemeleri, en iyi bildikleri bağlayıcıları mantıksal ilişkiyi sağlamak için kullanmaları da bu durumun nedenleri arasında görülebilir. Katılımcı öğrencilerin anılan 7 bağlayıcıyı başarılı biçimde kullanmalarının temelinde okudukları metinlerde bu bağlayıcılarla sık karşılaşmalarının etkisinin de olabileceği düşünülmektedir. Çünkü Memoğlu-Süleymanoğlu'nun (2006) yazınsal yapitlar, gazete ve dergiler, toplum, devlet, ekonomi ile ilgili yapıtlardan ve ders kitaplarından alınan yarım milyon metinler bütününün incelenmesiyle ortaya koyduğu sözcük sıklıklarına bakıldığında katılımcı öğrencilerin doğru kullandığı bağlayıcıların kullanım sıklıklarının en üstlerde yer aldığı görülmektedir. Anılan çalışmada "ve” bağlayıcısının incelenen kaynaklarda toplam 7862 sıklıkla en fazla kullanılan ikinci sözcük, "sonra" bağlayıcısının 1853 sıklıkla on beşinci sözcük olması katılımcı öğrencilerin bu bağlayıcıları neden en yetkin biçimde kullandığına ilişkin görüşü destekler niteliktedir. 
Edwards (2014) öğrencilerin "ve”, “sonra” bağlayıcıları başta olmak üzere birçok bağlayıcıyı yanlış ve aşırı kullandıklarını belirterek onların bağlayıcıları anlamaları ve doğru kullanmalarında yardımcı olabilecek şu önerileri sunmaktadır:

- Öğrencilerin kullanabilecekleri ve çalışabilecekleri bağlayıcı örnekleri bulma.

- Bağlayıcıların anlamları konusunda açıklama yapma.

- Bağlayıcıları konu edinen oyunlar oynama. (Örneğin, bir dizi bağlayıcının yer aldığı sözcük kartları hazırlanır. Çocuklar her bir bağlayıcıya uygun tümceler düşünüp türetirler.)

- Basit tümceleri bağlayıcı kullanarak birleştirme.

- Bağlayıcıları yanlış kullanma. (Çocuklar tasarlanmış yanlışı bulurlar ve düzeltirler.)

Yanlış kullanılma oranı \%31-50 arasında olan grupta ise 13 bağlayıcı yer almıştır. Bu grupta \%49.6 oranla en fazla yanlış kullanılan "böylece” ve "ilk olarak" bağlayıcılarının söylem belirteci olması dikkat çekmektedir.

Testte yer alan 36 bağlayıcıdan 16'sı katılımcı öğrencilerin yarısından fazlası tarafından yanlış kullanılmıştır. Bu grup içinde yer alan bağlayıcıların yapısal ve anlamsal özelliklerine bakıldığında 7 tanesinin alta siralama, 6 tanesinin söylem belirteci ve 3 tanesinin yana sıralama bağlayıcısı, ayrıca anlamsal açıdan bakıldığında 5 genişleme, 5 karşıtlık, 4 zamansallık ve 2 nedensellik anlamı bildiren bağlayıcılar olduğu görülmüştür. Bağlayıcılar içinde en fazla yanlış yapılanın söylem belirteci grubu içinde yer alan ve karşıtlık bildiren bağlayıcının "buna karşın" olduğu görülmüştür. Gençer'in (2013) Türkçe metinlerde yer alan bağlayıcılar ile iyi ve zayıf okuyucuların okuduğunu anlama durumları arasındaki ilişkiyi incelediği çalışmasının sonuçlarında, zayıf okuyucuların okuduğunu anlama durumları ile "karşıtlık" ve "genişleme" bildiren bağlayıcılar arasında negatif yönlü anlamlı bir ilişkinin saptandığı belirtilmektedir.

Yapısal özelliklerine göre sınıflandırılan 3 tür bağlayıcının altında anlamsal özelliklerine göre zamansal, nedensel, karşıtlık ve genişleme bildiren bağlayıcı türlerinin her birinden 3 ayrı madde oluşturularak toplam 36 maddelik bir test elde edilmiştir. 477 katılımcının oluşturduğu çalışma grubunun tümünün yalnızca bir anlamsal ulamda yer alan 3 ayrı maddenin tümünü yanlış yaptığı düşünüldüğünde maksimum yanlış sayısı 1431 olacaktır. Her bir yapısal sınıflandırma ulamının 12 madde içerdiği göz önünde bulundurulduğunda maksimum yanlış sayısının her bir ulam için 5724 olabileceği görülmektedir. Yapısal özelliklerine göre yapılan sınıflandırmada yer alan söylem belirteçleri 3100 (\%54.2), alta sıralama bağlayıcıları 2983 (\%52.1) ve yana sıralama bağlayıcıları $2035 \quad(\% 35.6) \quad$ kez katılımcılar tarafından yanlış kullanılmıştır. $\mathrm{Bu}$ sonuçlara göre, öğrencilerin yapısal özelliklerine göre en başarılı oldukları bağlayıcılar yana sıralama türündedir. Çetinkaya, Ülper ve Hamzadayı'nın (2014) 4., 8. ve 12. sınıf öğrencilerinin yazılı anlatımlarında bağlayıcı kullanım durumunu inceleyen çalışmasının sonuçları tüm sınıf düzeylerinde öğrencilerin en fazla yana sıralama bağlayıcılarını kullandıklarını göstermektedir. Anlamsal özelliklerine 
göre tanımlanan bağlayıcılar yapısal özellikleriyle birlikte değerlendirildiğinde en fazla yanlış yapılan ulam içinde söylem belirteci grubundan genişleme (\%61.4), alta sıralama grubundan zamansallık (\%63.2) ve son olarak yana sıralama grubundan karşıtlık (\%56) bildiren bağlayıcılar yer almıştır. Doğru kullanımı büyük oranda fazla olan bağlayıcı grubu içinde ise yana sıralama bağlayıcı grubu altında bulunup zamansallık ve nedensellik bildiren bağlayıcılar yer almıştır. Sonuçlar genel olarak değerlendirildiğinde öğrencilerin sözceler arasındaki anlamsal ya da mantıksal ilişkileri işaret eden bağlayıcıları doğru kullanma konusunda yetkin olmadığı söylenebilir. Benzer olarak, Cain, Patson ve Andrews'un (2005) 8-10 yaş grubu 145 öğrencinin bağlayıcı kullanım becerilerini incelediği çalışmasının sonuçları da yaş ilerledikçe öğrencilerin zamansal, nedensel ve karşıtlık bildiren bağlayıcıları daha başarılı kullandıklarını, fakat bağlayıcıların işaret ettiği anlamsal ilişkileri anlama konusunda gelişimin sürdüğünü göstermektedir.

Anlamsal özelliklerine göre sınıflandırılan bağlayıcıların öğrenciler tarafından yanlış kullanılma sıklık ve oranına bakıldığında en fazla yanlış kullanımın karşıtlık bildiren bağlayıcı içeren maddelerde yapıldığı, sonra sırasıyla genişleme, nedensellik ve zamansallık bildiren bağlayıcılarda yanlış yapıldığı görülmektedir. Daha önce de belirtildiği gibi, yapılan çalışmaların bulguları mantıksal ilişkilerin ediniminde genişleme, zamansallık, nedensellik ve karşıtlık biçiminde bir sıranın olduğuna işaret eder (Spooren \& Sanders, 2008). Bu çalışmanın veri tabanından elde edilen bulgulara göre yanlış kullanım sıklıkları alanyazında belirtilen edinim sırasıyla tam bir benzerlik sergilememektedir. "ve” bağlayıcısının en yetkin biçimde kullanılmış olması, öte yandan karşıtlık bildiren bağlayıcıların yanlış kullanım sıklıklarının en fazla olması örtüşen görünümlerdir.

Sonuç olarak, çalışmanın veri tabanını oluşturan 477 ortaokul öğrencisi alta sıralama, yana sıralama ve söylem belirteci grupları altında oluşturulmuş 36 maddelik ölçekte yer alan bağlayıcıları kullanma konusunda yetersiz bir görünüm sergilemiştir. Bağlayıcıların metin üretim ve okuduğunu anlama sürecindeki işlevlerinin önemi göz önünde bulundurulduğunda bağlayıcı bilgisinin değeri daha da belirginleşmektedir.

\section{Kaynakça}

Bae, J. (2001). Cohesion and coherence in children's written English: Immersion and English-only classes. Isues in Aplied Linguistics, 12, 51 - 8.

Cain, K., Patson, N., \& Andrews, L. (2005). Age-and ability- related differences in young readers' use of conjunctions. Journal of Child Language, 32(4), 877-892.

Can, R. (2012). Ortaöğretim öğrencilerinin bağdaşıklık araçlarını işlevlerine göre yazılı anlatımlarında kullanma becerileri. Erzincan Üniversitesi Eğitim Fakültesi Dergisi, 14(1), 157-182.

Cook, G. (1989). Discourse. Oxford: Oxford University Press.

Coşkun, E. (2005). Illköğretim öğrencilerinin öyküleyici anlatımlarında bă̆daşıklı, tutarlılık ve metin elementleri (Yayımlanmamış doktora tezi). Gazi Üniversitesi Eğitim Bilimleri Enstitüsü, Ankara. 
Crosson, A. C. \& Lesaux, N. K. (2013). Does knowledge of connectives play a unique role in the reading comprehension of English learners and English-only students? Journal of Research in Reading, 36(3), 241-260.

Çetinkaya, G., Ülper, H. \& Hamzadayı, E. (2014). Views on the use of connectives in students' written discourse. In H. Arslan, G. Rata, E. Kocatörük \& M. A. İçbay (Eds.). Multidisciplinary perspectives on education (471-476). Newcastle: Cambridge Scholars Publishing.

Dilidüzgün, Ş. (2008). Türkçe öğretiminde metindilbilimsel bağlamda uygulamalı bir yaklaşım (Yayınlanmamış doktora tezi). İstanbul Üniversitesi Sosyal Bilimler Enstitüsü, İstanbul.

Duggleby, S. J., Tang, W. \& Kuo-Newhouse, A. (2015). Does the use of connective words in written assessments predict high school students' reading and writing achievement? Reading Psychology, 36(8), 1-22.

Edwards, S. (2014). Supporting writing (Helping hands). London: David Fulton Publishers.

Gençer, Y. (2013). Türkçe metinlerdeki bağlantı öğeleri ile okuyucuların okuduğunu anlama durumları arasındaki ilişkinin incelenmesi (Yayımlanmamış yüksek lisans tezi). Niğde Üniversitesi Eğitim Bilimleri Enstitüsü, Niğde.

Günay, V. D. (2013). Metin bilgisi: Hem metin çözümleme hem de yaratıcı yazma. Papatya Yayıncılık Eğitim: İstanbul.

Güneş, F. (2014). Anlama modelleri. Dil ve Edebiyat Öğretimi Dergisi, 9, 59-74.

Halliday, M.A.K. \& Hasan, R. (1976). Cohesion in English. London and New York: Longman

Irwin, J. W., \& Pulver, C. J. (1984). Effects of explicitness, clause order and reversibility on children's comprehension of causal relationships. Journal of Educational Psychology, 76(3), 399-407.

Jin, W. (2001). A quantitative study of cohesion in chinese graduate students' writing: variations across genres and proficiency levels. Paper presented at the Symposium on Second Language Writing at Purdue University West Lafayette, Indiana.

Karatay, H. (2010). Bağdaşıklık araçlarını kullanma düzeyi ile tutarlı metin yazma arasındaki ilişki. Mustafa Kemal Üniversitesi Sosyal Bilimler Enstitüsü Dergisi, 13, 373-385.

Kintsch, W. \& Van Dijk, T.A. (1978). Toward a model of text comprehension and production. Psychological Review, 85, 363-394

Kurtul, K. (2011). Türkçe ve Ingilizce'deki bağlaçların yazllı metinlerde kullanımı (Yayımlanmamış doktora tezi). Ankara Üniversitesi Sosyal Bilimler Enstitüsü, Ankara.

McCarthy, M. (1991). Discourse analysis for language teachers. Cambridge: Cambridge University Press. 
Memoğlu-Süleymanoğlu, H. (2006). Türkçe’nin ters sıklık sözlüğ̈̈̈. Kurmay Kitap Yayın Dağıtım: Ankara.

Onursal, İ. (2003). Türkçe metinlerde bağdaşıklık ve tutarlılık. In A. Kıran, E. Korkut \& S. Ağ1ldere (Eds.). Günümüz Dil Bilim Çalışmalarl (121-133). Ankara: Multilingual Yayınları.

Seçkin, P., Arslan, N. ve Ergenç, S. (2014). Bağdaşıklık ve tutarlılık bakımından lise ve üniversite öğrencilerinin yazılı anlatım becerileri. Uluslararası Türkçe Edebiyat Kültür Eğitim Dergisi, 3(1), 340-353.

Spooren, W. \& Sanders, T. (2008). The acquisition order of coherence relations: On cognitive complexity in discourse. Journal of Pragmatics, 40, 2003-2026.

Turan, Ü. D., Zeyrek, D. ve Bozşahin, C. (2012). Söylem ve bağdaşıklık ilişkileri. Dilbilim Araştırmaları Dergisi, 2012(II), 40-65.

Uzun, L. (2006). Öğrencilerin yazılı anlatım sürecindeki metinleştirme sorunlarl. II.Ulusal Çocuk ve Gençlik Edebiyatı Sempozyumu (s. 693-701). Ankara: Ankara Üniversitesi. 